\title{
COVID-19 Pandemic Recession, Policy Response, and Recovery: A Canadian Perspective
}

\author{
Nusrate Aziz, Thomas Barber, Marisa Stopes \\ School of Business and Economics, Algoma University
}

\begin{abstract}
The purpose of this paper is to explain the economic impact of the Covid-19 pandemic on Canada's economy and the response by the monetary authority. We also explain a potential adjustment process on the way to recover from the pandemic recession.
\end{abstract}

Problems, Policy, and Response: The recent pandemic has had an unprecedented impact on the global economy. Arriving in North America in late January (Stobbe \& Johnson, 2020), COVID19 has caused a massive restructuring of various industries in the Canadian economy, with many Canadians facing unemployment, or uncertainty about their future potential of financial and physical well-being.

A textbook model of Aggregate Demand (AD) and Aggregate Supply (AS) can help better understand the macroeconomic impact of the COVID-19 crisis as it evolves. Typically, the ASAD model can analyze the economic impact of COVID-19.

Sectors that had significantly reduced supply from February to May 2020 due to the COVID-19 crisis included food services and accommodation (-39\%), food and beverage products (-8\%), motion pictures (-53\%), and construction (-9\%) (Baqaee \& Farhi, 2020). This reduction in supply was likely due to stay-at-home lockdowns, and social distancing measures. Other sectors that had significantly reduced demand were air transportation (-39\%), water transportation $(-30 \%)$, rail transportation (-18\%), petroleum and coal $(-18 \%)$, and oil and gas extraction $(-17 \%)$ (Baqaee $\&$ Farhi, 2020). This strain in demand tells us that consumers were spending less on transportation methods, and this trickled into the fossil fuel sector. In response to this reduced demand, companies, for example, Air Canada laid off about 20,000 employees (Wright, 2020).

In the second quarter of 2020, there was a record decline in household spending affecting both goods $(-8.4 \%)$ and services $(-16.7 \%)$ (Statistics Canada, 2020a). This means that consumers have spent significantly less amount of money, and the velocity of money has declined as a result. The reduction in spending may be due to the unemployment rate of $13 \%$ in the second quarter for Canada (Statistics Canada, 2020). This sudden fall in consumer spending resulted in a substantial fall in demand for many firms. However, there are a few industries that received super extra profit include grocery stores, and online retail, among others. Retail e-commerce sales reached $\$ 3.2$ billion in September 2020 and rose 75\% on a year-over-year basis (Statistics Canada, 2020b). To meet the increased demand, food prices have risen $2.3 \%$ on a year-over-year basis in September 2020 (Statistics Canada, 2020b).

These rapid changes in the economy lead to an unprecedented mix of demand and supply shocks to the economy. Supply and demand shocks disrupt the economy by pushing output and employment away from their natural levels (Mankiw \& Scarth, 2020). Figure 1 explains the macroeconomic impact of the pandemic recession. 
FIGURE 1: Pandemic Crisis and AD-AS Shock

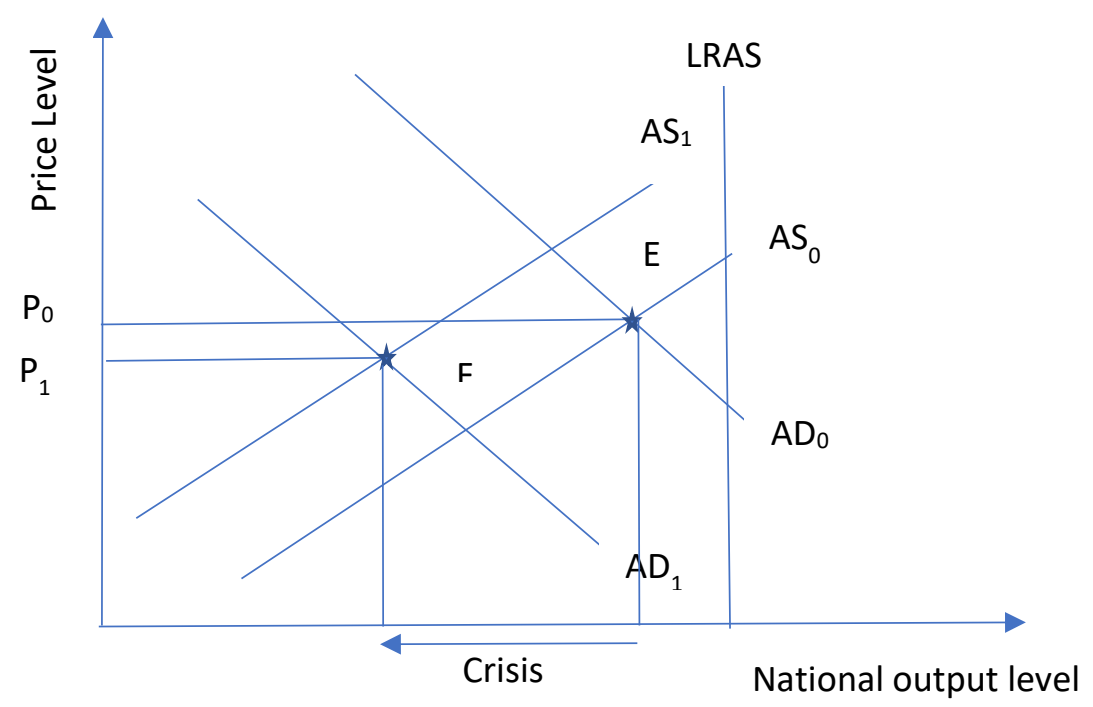

The figure shows the initial equilibrium point $\mathrm{E}$ was very close to the full employment level of output before the pandemic began. Increased unemployment rate (approximately 12-15 percent) due to COVID-19 decreased a significant amount of aggregate demand from $\mathrm{AD}_{0}$ to $\mathrm{AD}_{1}$. Businesses and production units were closed due to lockdown resulting in a significant decrease in aggregate supply to $\mathrm{AS}_{1}$. Consequently, there was a pandemic recession resulting in negative output growth. In a static model, we can show the new equilibrium at point F. Since production has been interrupted significantly by the COVID-19 crisis, generally, we may expect a high rate of inflation during this period. However, the reality was different. We saw a lower level of inflation during the pandemic recession (2020-2021) in the first three-quarters of the pandemic. People might consider the low level of inflation during the pandemic crisis as a surprise. However, this is not a surprise at all. A decrease in production, a significant interruption in the supply chain, and a decrease in aggregate demand (due to job loss) cause the rate of inflation to be lower (at $\mathrm{P}_{1}$ level) due to a shift of both AD and AS.

The question is now how the economy will recover from the COVID-19 pandemic crisis. Let us consider both the fiscal and monetary policies that are taken by the Canadian government and the Bank of Canada. 
FIGURE 2: Recovery policies and the impact (IS-LM framework)

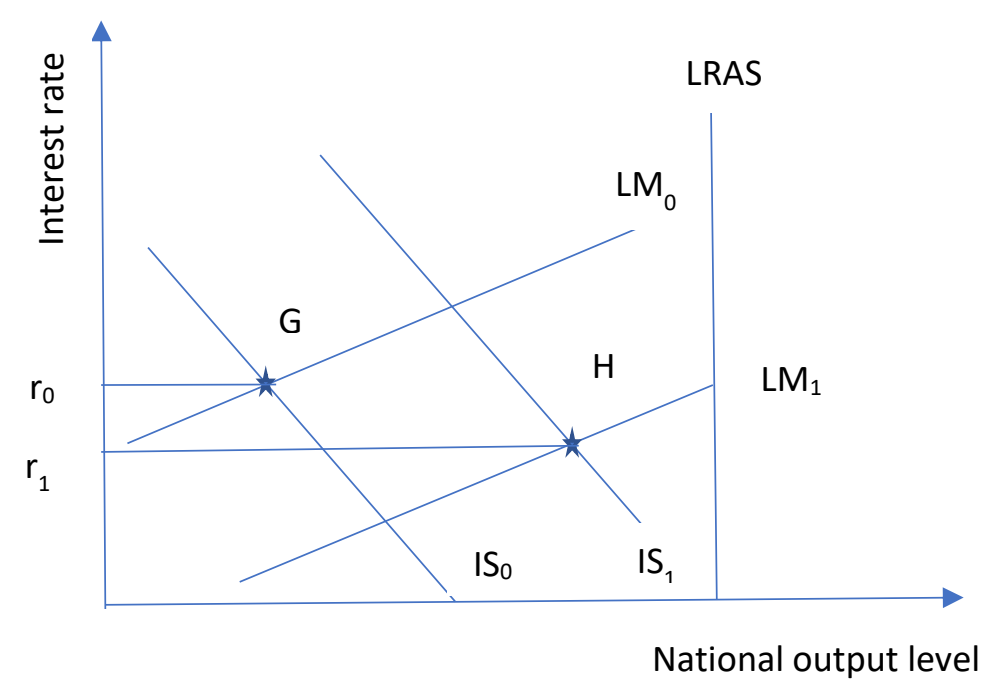

Figure 2 explains the policies implemented by the Canadian economy and the short-run and long-run responses to the policies. Canadian government implemented an expansionary fiscal policy i.e., the government financed the economy with a huge COVID-19 crisis recovery stimulus package of $\mathrm{C} \$ 107$ billion (March 2020) as emergency aid and economic stimulus, and $\$ 100$ billion for post-pandemic recovery (December 2020). The Bank of Canada simultaneously implemented an expansionary monetary policy by lowering the policy rate to a record low of $0.25 \%$ (Bank of Canada, 2020). Due to a quick simultaneous response from both the fiscal and monetary sides, the economy has been in a recovery process for the last few quarters now. Figure 2 shows that both the IS and the LM curves shift to the right, from $\mathrm{G}$ which is expected to reach around equilibrium $\mathrm{H}$, eventually. Due to employment insurance and the Federal and Provincial government's support to households and employees' wage support to businesses, the aggregate demand and aggregate supply have already recovered to some extent. It is expected to increase over time. The speed of adjustment to the new equilibrium $\mathrm{H}$ will perhaps depend on the speed to normalization of the economy and re-opening the businesses by administering the COVID-19 vaccine sooner than later. According to the Public Health Agency of Canada, approximately $67 \%$ of the total Canadian population have received at least one dose of vaccine, and $36 \%$ are fully vaccinated as of July 12 , 2021. It shows that Canada is performing well in the COVID-19 vaccination program.

Inflation is not high right now. However, in the long run, wages will increase due to an increase in production. Employees will ask for their fair share in business profit which will lead to an increase in the price level. The economy will also reach its natural level of production again. 
Figure 3: Short-run to long-run dynamic adjustment path (AD-AS Framework)

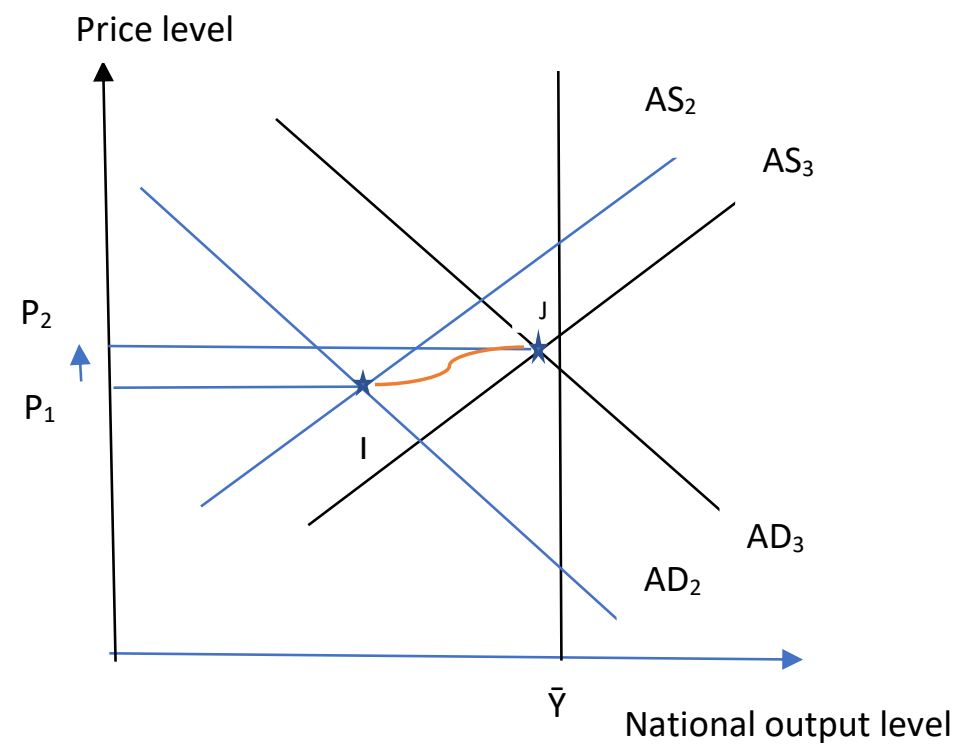

Figure 3 shows a potential adjustment path for the Canadian economy post- COVID-19 pandemic crisis using the AD-AS framework. The price level is not high yet due to a simultaneous and adverse demand and supply shock. The expected price level adjustment to the long run will be upward, and the economy will recover to its natural level of output. Due to technological advancement for the economy to reach from I to $\mathrm{J}$ might not cost much inflation. Of course, the central bank has sufficient tools for inflation targeting too.

Figure 4: Canadian Economic Recovery

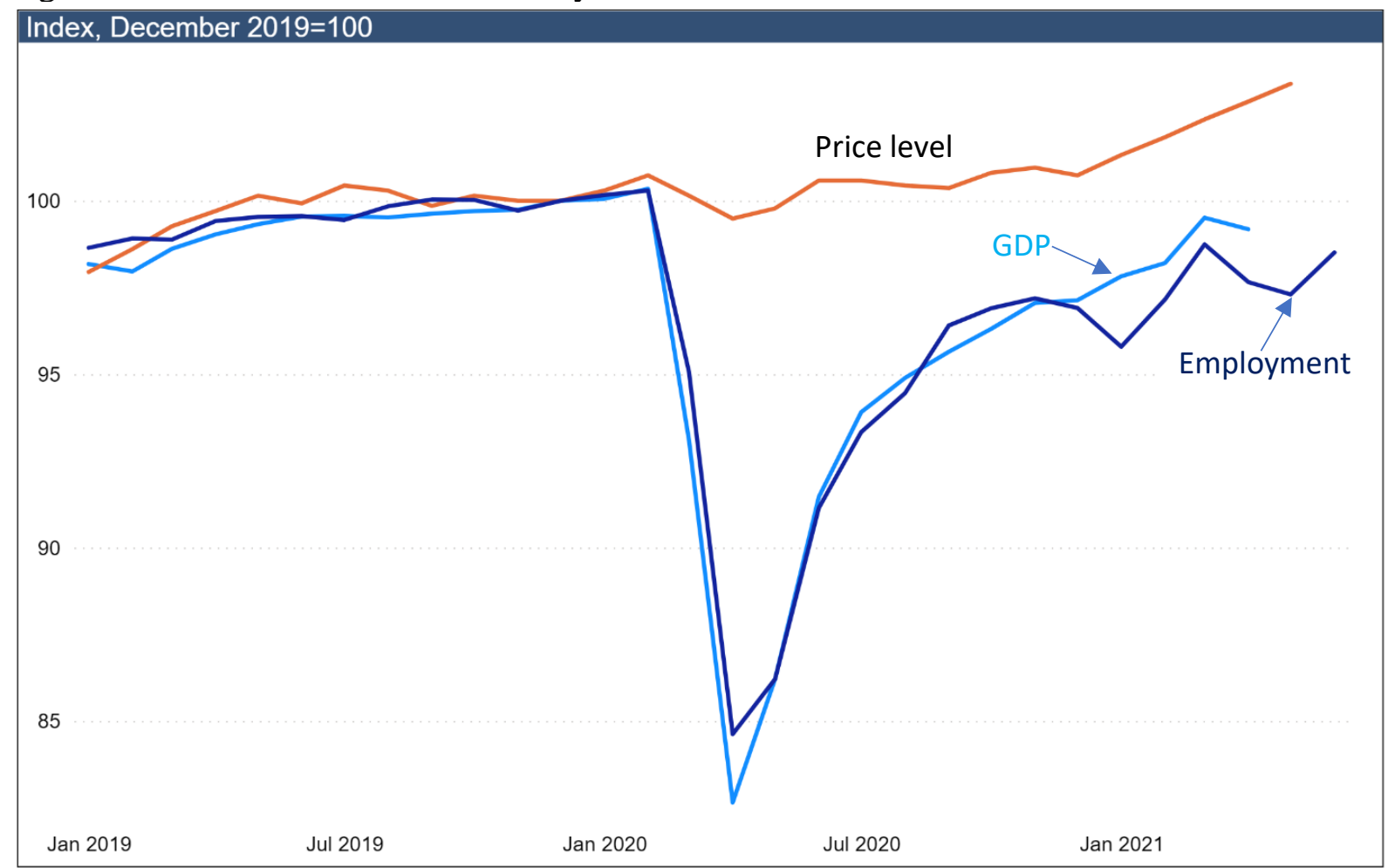

Source: Statistics Canada (2021) 
Figure 4 shows Canada's economic recovery over time that supports our theoretical prediction.

Conclusion: In 2020, Canada, like many other countries, injected a lot of money into the economy to fight the economic slowdown. At the same time, the monetary authority reduced the interest rates to a record low to make borrowing easy. A potential consequence is a high rate of inflation. Besides, in a situation like this, an imbalance between demand and supply of goods and services leads the economy to a short-term disequilibrium. It takes time for the economy to adjust the supply following increased demand. Not only production, but the supply chain also matter in this circumstance. After a few uneven fluctuations, however, the economy is expected to adjust towards its natural level in terms of production, employment, supply, and demand in the long run.

\section{Reference}

Bank of Canada. (2020). Monetary Policy Report: December 2020. Ottawa, Ontario: Bank of Canada.

Baqaee, D., \& Farhi, E. (2020, June 29). Supply versus demand: Unemployment and inflation in the COVID-19 recession. Retrieved from Vox EU: https://voxeu.org/article/assessingkeynesian-spillovers-covid-19-recession

Mankiw, N., \& Scarth, W. M. (2020). Macroeconomics: Canadian Edition. Worth Publishers.

Public Health Agency of Canada (2021). Canadian report on COVID-19 vaccine doses administered. Ottawa: Public Health Agency of Canada; July 12, 2021. https://healthinfobase.canada.ca/covid-19/vaccine-administration/

Statistics Canada. (2020a). Gross domestic product, income and expenditure, second quarter 2020.

Statistics Canada. (2020b). Canadian economic dashboard and COVID-19. Retrieved from Statistics Canada: https://www150.statcan.gc.ca/n1/pub/71-607-x/71-607-x2020009eng.htm

Statistics Canada (2021). Canadian Economic Dashboard and COVID-19. https://www150.statcan.gc.ca/n1/pub/71-607-x/71-607-x2020009-eng.htm

Stobbe, M., \& Johnson, C. (2020). First coronavirus case confirmed in the United States. . Retrieved from CTV News: https://www.ctvnews.ca/health/first-coronavirus-caseconfirmed-in-united-states-1.4777218.

Wright, T. (2020, May 16). As Air Canada announces layoffs, feds continue conversation on possible help. Retrieved from National Observer: https://www.nationalobserver.com/2020/05/16/news/air-canada-announces-layoffs-fedscontinue-conversation-possible-help 